Ann. Biol. anim. Bioch. Biophys., I97I, 11 (3), 499-503.

\title{
INFLUENCE D'UNE CONSERVATION DE LONGUE DUREE SUR LA VALEUR NUTRITIVE DES PROTÉINES DU BLÉ ET SUR LEUR VITESSE D'HYDROLYSE ENZYMATIQUE IN VITRO
}

\author{
Denise HUGOT, M. SUSCHETET et J. CAUSERET \\ Station de Recherches sur la Qualité des Aliments de l'Homme, \\ Centre de Recherches agronomiques, I. N.R. A., \\ 21 -Dijon
}

Au cours d'un travail récent, Pawlak et Pion (1970) ont étudié l'influence de la conservation sur la valeur nutritive des protéines du blé, en utilisant comme critères d'évaluation le croît du jeune Rat et la teneur du sang et du muscle en deux acides aminés libres (lysine, thréonine).

Les travaux qui font l'objet de la présente note ont été effectués sur trois des échantillons étudiés par PAWLAK et PION, à savoir des blés Cappelle, d'une même origine, stockés durant 2 ans dans différentes conditions :

- sous atmosphère d'azote

- en cellule ventilée

- dans un congélateur, à - $20^{\circ} \mathrm{C}\left({ }^{1}\right)$

Les critères d'évaluation suivants ont été employés :

- utilisation digestive et valeur biologique des protéines (chez le jeune Rat) ;

- effets des blés, supplémentés ou non en différents acides aminés, sur l'évolution pondérale du Rat ;

- vitesse de protéolyse in vitro.

\section{I. - Utilisation digestive et valeur biologique des protéines}

Quatre lots de ro jeunes rats mâles Wistar âgés initialement de 28 jours, provenant de l'élevage de la Station, ont été soumis successivement à un même régime protéiprive, puis, après une période de récupération, à différents régimes contenant comme seule source de protéines (au taux de 10,4 p. roo de la matière sèche), soit l'un des 3 échantillons de blé, soit de la poudre d'ouf (tabl. I). La consommation de nourriture des rats recevant le régime à base de poudre

(1) Ces échantillons ont été fournis par le Centre national d'Études et d'Expérimentation de Machinisme agricole (Antony). 
d'œuf a été alignée sur la moyenne des consommations (très voisines) des trois lots recevant du blé.

TABLEAU I

Régimes alimentaires (en p. roo)

\begin{tabular}{|c|c|c|c|}
\hline & $\begin{array}{c}\text { Régime } \\
\text { protéiprive }\end{array}$ & $\begin{array}{c}\text { Régime } \\
\text { à base de blé }\end{array}$ & $\begin{array}{c}\text { Régime } \\
\text { à base d'œuf }\end{array}$ \\
\hline Blé ............ & 一 & 87 & - \\
\hline Poudre d'œuf ... & - & - & 20 \\
\hline Saccharose ..... & 32 & - & 20 \\
\hline Amidon ......... & 50 & - & 50 \\
\hline Huile de maîs ... & 12 & 7 & 4 \\
\hline Mélange salin .... & 4 & 4 & 4 \\
\hline Agar Agar ..... & 2 & 2 & 2 \\
\hline Mélange vitami- & & & \\
\hline nique...$\ldots \ldots$ & + & + & + \\
\hline
\end{tabular}

Pour chacun des 4 lots, on a calculé le coefficient d'utilisation digestive et la valeur biologique des protéines du régime, ainsi que l'utilisation protéique nette :

$$
\begin{gathered}
\mathrm{CUD}=\frac{\left(\mathrm{I}-\mathrm{I}_{0}\right)-\left(\mathrm{F}-\mathrm{F}_{0}\right)}{\mathrm{I}} \times 100 \\
\mathrm{VB}=\frac{\left(\mathrm{I}-\mathrm{I}_{0}\right)-\left[\left(\mathrm{F}-\mathrm{F}_{0}\right)+\left(\mathrm{U}-\mathrm{U}_{0}\right)\right]}{\left(\mathrm{I}-\mathrm{I}_{0}\right)} \times 100 \\
\mathrm{UPN}=\frac{\mathrm{CUD} \times \mathrm{VB}}{\mathrm{I00}}
\end{gathered}
$$

où $\mathrm{I}_{0}, \mathrm{~F}_{0}, \mathrm{U}_{0}$ sont respectivement les quantités d'azote ingérées et éliminées par les fèces et l'urine durant la période d'alimentation protéiprive ; et I, F, U, les quantités correspondantes durant la période d'alimentation avec azote.

Les résultats sont mentionnés dans le tableau 2 :

\section{TABLEAU 2}

\begin{tabular}{|c|c|c|c|}
\hline Source de protéines & CUD & VB & UPN \\
\hline $\begin{array}{l}\text { Ble sous azote } \ldots . \\
\text { Ble en cellule ven- } \\
\text { tilee } \ldots \ldots \ldots \ldots . . . \\
\text { Ble à }-20^{\circ} \mathrm{C} \ldots \\
\text { CEuf } \ldots \ldots \ldots \ldots\end{array}$ & $\begin{array}{l}80,2 \pm 0,54 \\
79,5 \pm 1,09 \\
79,2 \pm 0,99 \\
89,0 \pm 1,49\end{array}$ & $\begin{array}{l}45,4 \pm 1,40 \\
43,3 \pm 1,33 \\
41,6 \pm 2,03 \\
90,0 \pm 0,79\end{array}$ & $\begin{array}{l}36,4 \pm 1,27 \\
34,5 \pm 1,32 \\
33,1 \pm 1,85 \\
80,1 \pm 1,68\end{array}$ \\
\hline
\end{tabular}

Coefficient d'utilisation digestive (CUD), Valeur biologique (VB) et Utilisation protéique nette (UPN) des produits étudiés

N. B. Les valeurs moyennes sont suivies de l'erreur standard. 
On voit que le CUD, la VB et I'UPN des protéines des trois échantillons de blé sont nettement inférieurs à ceux des protéines d'œuf, mais qu'ils diffèrent peu les uns des autres, les faibles différences obtenues n'étant d'ailleurs pas significatives.

\section{2. - Effets sur l'évolution pondérale du Rat}

a) Les animaux utilisés pour les déterminations précédentes ont été maintenus aux régimes à base de blés ou d'œuf durant 3 semaines, en vue de déterminer leur croît et leur consommation de nourriture (tabl. 3 ).

\section{TABLEAU 3}

Crốt et consommation des animaux soumis à des régimes à base de blés non supplémentés en acides aminés

\begin{tabular}{|c|c|c|}
\hline Source de protéines & $\begin{array}{l}\text { Gain de poids } \\
\text { g/jour }\end{array}$ & $\begin{array}{c}\text { Consommation de } \\
\text { régime } \\
\text { g secs/jour }\end{array}$ \\
\hline $\begin{array}{l}\text { Blé sous azote } \ldots \ldots \ldots \\
\text { Blé en cellule ventilée } \\
\text { Blé à }-20^{\circ} \mathrm{C} \ldots \ldots \ldots \\
\text { Guf } \ldots \ldots \ldots \ldots \ldots \ldots\end{array}$ & $\begin{array}{l}1,3 \pm 0,09 \\
1,7 \pm 0,11 \\
1,5 \pm 0,08 \\
3,9 \pm 0,05\end{array}$ & $\begin{aligned} & 9,8 \pm 0,42 \\
& 10,8 \pm 0,33 \\
& 10,4 \pm 0,26 \\
& 10,3 \text { (consomma- } \\
& \text { tion alignée) }\end{aligned}$ \\
\hline
\end{tabular}

N. B. Les valeurs moyennes sont suivies de l'erreur standard.

Pour les trois régimes à base de blé, les gains de poids sont beaucoup plus faibles que pour le régime à base d'œuf, mais ne présentent entre eux que de faibles différences ; celles-ci sont dues principalement à des différences dans les niveaux de consommation.

b) Dans une autre série d'expériences, 3 lots de 40 jeunes rats (20 mâles et 20 femelles), âgés initialement de 28 jours, ont été soumis, durant 18 mois, à des régimes identiques aux régimes "blés " des essais précédents, mais dans lesquels les blés étaient supplémentés en DL-méthionine (o,I4 p. I0o), L-tryptophane (0,07 p. roo), L-thréonine $(0,26$ p. Ioo) et L-lysine (o, 8 p. roo).

Le gain de poids et la consommation de nourriture ont été déterminés durant les trois premières semaines (tabl. 4).

\section{TABLEAU 4}

Croît et consommation des animaux soumis à des régimes

à base de blés supplémentés en acides aminés

\begin{tabular}{|c|c|c|c|c|}
\hline \multirow{2}{*}{$\begin{array}{c}\text { Sources de } \\
\text { protéines } \\
\text { (supplémentées) }\end{array}$} & \multicolumn{2}{|c|}{ Mâles } & \multicolumn{2}{|c|}{ Femelles } \\
\hline & $\begin{array}{l}\text { Gain de poids } \\
\text { (g/jour) }\end{array}$ & $\begin{array}{l}\text { Consommation } \\
\text { (g secs/jour) }\end{array}$ & $\begin{array}{l}\text { Gain de poids } \\
\text { (g/jour) }\end{array}$ & $\begin{array}{c}\text { Consommation } \\
\text { (g secs/jour) }\end{array}$ \\
\hline $\begin{array}{l}\text { Blé sous azote } \ldots \\
\text { Blé en cellule ven- } \\
\text { tilée } \ldots \ldots \ldots \ldots \\
\text { Blé a }-20^{\circ} \mathrm{C} \ldots\end{array}$ & $\begin{array}{l}6,3 \pm 0,08 \\
6,2 \pm 0,06 \\
6,4 \pm 0,06\end{array}$ & $\begin{array}{l}16,3 \pm 0,13 \\
16,2 \pm 0,13 \\
16,6 \pm 0,17\end{array}$ & $\begin{array}{l}3,7 \pm 0,08 \\
3,5 \pm 0,09 \\
3,4 \pm 0,15\end{array}$ & $\begin{array}{l}13,8 \pm 0,22 \\
13,7 \pm 0,18 \\
14,1 \pm 0,19\end{array}$ \\
\hline
\end{tabular}

N. B. Les valeurs moyennes sont suivies de l'erreur standard. 
Par la suite, et jusqu'à la fin du I $8^{\mathbf{e}}$ mois d'expérience, l'évolution pondérale des animaux de chaque sexe est restée très voisine dans les trois lots, les faibles différences observées n'étant pas significatives. La consommation de nourriture n'a plus été déterminée en permanence, mais elle a fait l'objet d'une évaluation pendant 28 jours après 4 mois d'expérience ; aucune différence significative n'a été observée entre les trois lots.

\section{3. - Vitesse de protéolyse in vitro}

La vitesse de protéolyse de broyats provenant des trois échantillons de blé a été étudiée en présence :

- de pepsine (agissant 30 minutes)

- de trypsine (agissant 30 minutes)

- de pepsine (3o minutes) puis de trypsine (30 minutes).

Ces broyats ont été obtenus au moyen d'un moulin de laboratoire Bühler. Les hydrolyses ont été réalisées dans des tubes à centrifuger, la réaction étant arrêtée, au moment choisi, par addition d'acide trichloracétique. Après centrifugation, l'azote soluble a été dosé dans le surnageant par la méthode de Kjeldahl.

Les pourcentages d'azote soluble rapportés à l'azote total sont mentionnés dans le tableau $\mathbf{5}$.

TABLEAU 5

Taux d'hydrolyse enzymatique des blés

(rapport $\mathrm{N}$ soluble/N total, exprimé en p. Ioo)

\begin{tabular}{c|c|c|c}
\hline \hline Blé & $\begin{array}{c}\text { Hydrolyse } \\
\text { pepsique }\end{array}$ & $\begin{array}{c}\text { Hydrolyse } \\
\text { trypsique }\end{array}$ & $\begin{array}{c}\text { Hydrolyse } \\
\text { pepsique et } \\
\text { trypsique }\end{array}$ \\
\hline Blé sous azote ......... & 43 & 24 & 78 \\
Blé en cellule ventilée.... & 43 & 24 & 77 \\
Blé à $-20^{\circ} \mathrm{C} \ldots \ldots \ldots \ldots \ldots$ & 43 & 24 & 76 \\
\hline
\end{tabular}

Aucune différence entre blés n'a été observée.

\section{Conclusions}

L'utilisation digestive et la valeur biologique des protéines des trois échantillons de blé ont été identiques, ainsi que l'évolution pondérale des trois lots de rats recevant ces échantillons (supplémentés ou non en certains acides aminés) comme seule source d'azote. L'étude de la vitesse de protéolyse n'a pas permis non plus d'observer de différences entre échantillons.

Ces résultats confirment les conclusions du travail antérieur de PawLak et Pion : il paraît possible de conserver du blé pendant plusieurs années sans modifier sa valeur comme source de protéines. 


\section{SUMMMARY}

EFFECT OF PRESERVATION FOR A LONG TIME ON THE NUTRITIVE VALUE

OF PROTEINS OF WHEAT AND THEIR RATE OF ENZYMATIC HYDROLYSIS IN VITRO

Nutrive value of proteins of a Cappelle wheat was studied in rats, after storage for 2 years under nitrogen, in a ventilated container or in a freezer at $-20^{\circ} \mathrm{C}$; the last sample was considered the control. Digestive utilisation and biological value of the proteins of these samples were the same. It was the same for weight changes of the rats given the samples, supplemented or not with certain amino acids, as the only source of nitrogen.

A study of proteolysis, by pepsin, by trypsin and successively by these two enzymes also did not show any difference among the wheats studied.

These results confirm the conclusions from an earlier work of Pawlak and Pion : it would seem possible to preserve wheat for several years without changing its value as a source of protein.

\section{RÉFÉRENCES BIBLIOGRAPHIQUES}

Pawlak M., Pion R., I97o. Influence de la conservation sur la valeur nutritive des protéines du blé. Ann. Biol. anim. Bioch. Biophys., 10, 17I-174. 